\title{
USE OF EXPANDED POLYSTYRENE (EPS) BEADS IN SILICA-FUME CONCRETE
}

\author{
LAWEnd K. ASKar ${ }^{*}$, ISMael H. Mosa AlbarWary ${ }^{* *}$ and MAND K. ASKar * \\ *Technical College of Engineering ;Duhok Polytechnic University; Kurdistan Region, Iraq \\ ** Dept. of Road Construction ;Duhok Technical Institute ;Duhok Polytechnic University; Kurdistan Region, Iraq
}

(Received: September 26, 2018; Accepted for Publication: February 6, 2019)

\begin{abstract}
Concrete is a good constructional material as it posses enough compressive strength for structural purposes, in spite of that concrete has some dis-advantages, one of these main dis-advantages is its high density $(2300-2400) \mathrm{kg} / \mathrm{m}^{3}$.Many trials were made to minimize its density in different ways. Recently Expanded Polystyrene (EPS) granules $(98 \%$ air) were added to the concrete for this purpose. In this investigation the concrete density is reduced by adding polystyrene granules to the silica-fume concrete. Silica-fume was added for enhancing the concrete strength and balances the loss in concrete strength due to the inclusion of polystyrene granules .Test results show that the inclusion of silica fume to the concrete improves its strength for both normal concrete and concrete of EPS beads. It is concluded that structural concrete (Strength > $17 \mathrm{MPa}$ ) with EPS beads can be manufactured when silica fume is added to concrete.
\end{abstract}

\section{KEYWORDS: Compressive Strength, Silica Fume, Polystyrene Granules, light weight concrete}

\section{INTRODUCTION}

Concrete is a good constructional material as it posses enough compressive strength for structural purposes, in spite of that concrete has some disadvantages ,one of these main dis-advantages is its high density $(2300-2400) \mathrm{kg} / \mathrm{m}^{3}$.Many trials were made to minimize its density by manufacturing lightweight concrete. Lightweight concrete was manufactured traditionally by three methods which are;-

A. Using lightweight aggregates like pumice or scoria.

B. Introducing air bubbles in the mortar.

C. Omitting sand from the concrete.

A new technique was used to manufacture lightweight concrete by adding light weight materials (cork and agricultural waste materials) as partially or full replacement of fine or coarse aggregates.

Recently Expanded Polystyrene (EPS) beads and granules which are lighter (98\% air) were added to the concrete to minimize it density, herein the review of the researches and investigations about using this material in concrete;-

Bing Chen,Jie Liu and Long-zhu Chen (1) Used the expanded polystyrene beads as totally or partially replacement of the fine or coarse aggregate ,they do that to develop a new lightweight concrete, the beads used were 1,2.5 and $6.3 \mathrm{~mm}$ size ,also silica fume and polypropylene fibers were used to improve the concrete properties.

Test results show that the silica-fume increases the bond between cement paste and polystyrene beads. Also they concluded that strength of polystyrene concrete decreases linearly with the increase of EPS fraction in concrete.

Hind M. Ewadh and Noorezlin A. Basri (2) studied the effect of using polystyrene beads in concrete on the absorption and workability of concrete. Different ratios of polystyrene beads $25 \%, 50 \%, 75 \%$, and $100 \%$ ) replacement of sand or gravel are used. They concluded that both the workability and absorption of concrete increases with the increasing of polystyrene beads and for $100 \%$ aggregate replacement by polystyrene beads the absorption was $82 \%$.

Tengku Fitriani L.Subhan (3) examined the properties (compressive and tensile strength) of lightweight concrete with EPS beads .Their result showed that the polystyrene beads amount in concrete affects the concrete strength inversely, and for the concrete with $15 \%$ polystyrene beads, the compressive strength was $86 \%$ compared to those of normal concrete.

Loh Wai Kin and Mohd Azreen Mohd Ariffin (4) Studied wall frame composite made from polystyrene beads and cold formed steel. For this 
purpose they examined three concrete mixes of $(1: 3.5: 2, \quad 1: 2.5: 3$, and 1:3.5:4 (cement sand, polystyrene beads)).

In this study the mix $(1: 3.5: 2)$ shows the highest compressive strength and therefore it was used in the wall frame composite.

Aman Mulla and Amol Shlake (5) tried to find light weight concrete mix of better properties than the burnt brick (compressive and density), expended polystyrene (EPS)beads were used in concrete as replacement of aggregate (5\%, $10 \%, 15 \%, 20 \%$, and $25 \%$ ). Their conclusion indicates that the concrete strength reduces with the increase in amount of the EPS beads; they also concluded that (EPS) beads concrete has only scope of using in non-structural applications.

Roshan Gawale et al.(6) completely replaced the coarse aggregate of concrete by EPS beads and examined the concrete properties .They found that lightweight with EPS beads can be used for the construction of partition walls and bed concretes.

Suhad M Abd et al.(7) replaced the fine aggregate partially(5\%, 15\%, and 20\%) by polystyrene beads and compared it with the normal concrete. They concluded that workability of concrete increases with the increase in polystyrene beads amount, while the density of concrete decreases with increase in polystyrene beads percent. They also concluded that using polystyrene beads in concrete helps as a solution for polystyrene beads disposal.

Wenbo Shi et al.(8) Produced EPS concrete by mixing expanded polystyrene beads with polymer emulsion and add it to the concrete. EPS was added by volume ratio of $0 \%, 20 \%, 30 \%$, and $40 \%$ by replacing the matrix or the gravel. They concluded that the compressive strength of the two types of EPS concrete in which the matrix is replaced by EPS or the gravel is replaced by EPS is identical. Another conclusion is that the EPS concrete can be used in some long term of cyclic dynamic load engineering.

Costin Andrei Cadere et al.(9) studied the influence of the inclusion of fly-ash (10\%) and polystyrene granules as replacement of aggregate on the density and mechanical properties of concrete (compressive, flexure and splitting tensile strength).

They concluded that the polystyrene granules decreases the concrete density and also decreases all types of concrete strengths except the tensile strength.

Observing the above review it is shown that in the most of researches, one type of the aggregate (sand or gravel) is usually replaced by EPS beads and the researches not deal with the EPS beads as an admixture to be added to the total volume of concrete.

In this investigation a trial was made to reduce the concrete density by adding polystyrene granules to the silica-fume concrete. Silica-fume was added for enhancing the concrete strength ( $10,11)$ and it is expected to balance the loss in concrete strength due to the inclusion of polystyrene granules $(1,5,9)$.

In this research it has been deal with the adding materials (silica fume and EPS beads) to the concrete as admixtures as Neville (12) illustrates that admixture is any material other than water, cement, and aggregates that used as an ingredient of concrete.

\section{Experimental Program}

A total of 60 cubical specimens were made in three main groups (A, B, and C). Each group consists of 20 specimens. The first group (Group A) includes specimens with EPS beads by concrete volume ratios of $(0 \%, 10 \%, 15 \%, 20 \%$, and $25 \%$ ) with out silica-fume content. .The second group (Group B) includes specimens with EPS beads by concrete volume ratios of $(0 \%$, $10 \%, 15 \%, 20 \%$, and $25 \%$ ) with silica-fume content of $5 \%$ replaced by cement weight. The third group (Group C) includes specimens with EPS beads by concrete volume ratios of $(0 \%$, $10 \%, 15 \%, 20 \%$, and $25 \%$ ) with silica-fume content of $10 \%$ replaced by cement weight. The silica fractions $(5 \%$ and $10 \%)$ were chosen according to ASTM C1240-04 (13) advisement which is from (5\%-12\%).Maximum Expanded polystyrene granules fraction $(25 \%)$ is controlled by the concrete workability, because the addition of the polystyrene beads reduces the concrete workability and after this ratio the concrete becomes non-workable.

For each variable studied in present investigation, four identical specimens were tested using the same mixing, curing and testing conditions. The details of the parameters or variables which were depended in current experimental investigation are listed in Table (1). 
Table (1): Parameters or variables which were studied in current experimental investigation

\begin{tabular}{|c|c|c|c|c|c|}
\hline Group & Mix NO. & $\begin{array}{l}\text { Mix } \\
\text { Proportions }\end{array}$ & $\begin{array}{l}\text { EPS Beads } \\
\text { by } \\
\text { Volume } \%\end{array}$ & $\begin{array}{l}\% \text { Silica- } \\
\text { Fume }\end{array}$ & $\begin{array}{l}\text { No. of } \\
\text { cubes }\end{array}$ \\
\hline \multirow{5}{*}{$\begin{array}{l}\text { Group } \\
\text { (A) }\end{array}$} & Mix 1 & $1 ; 1.73 ; 2.95 ; 0.5$ & $0 \%$ & $0 \%$ & 4 \\
\hline & $\operatorname{Mix} 2$ & $1 ; 1.73 ; 2.95 ; 0.5$ & $10 \%$ & $0 \%$ & 4 \\
\hline & $\operatorname{Mix} 3$ & $1 ; 1.73 ; 2.95 ; 0.5$ & $20 \%$ & $0 \%$ & 4 \\
\hline & Mix 4 & $1 ; 1.73 ; 2.95 ; 0.5$ & $15 \%$ & $0 \%$ & 4 \\
\hline & Mix 5 & $1 ; 1.73 ; 2.95 ; 0.5$ & $25 \%$ & $0 \%$ & 4 \\
\hline \multirow{5}{*}{$\begin{array}{l}\text { Group } \\
\text { (B) }\end{array}$} & $\operatorname{Mix} 6$ & $1 ; 1.73 ; 2.95 ; 0.5$ & $0 \%$ & $5 \%$ & 4 \\
\hline & $\operatorname{Mix} 7$ & $1 ; 1.73 ; 2.95 ; 0.5$ & $10 \%$ & $5 \%$ & 4 \\
\hline & Mix 8 & $1 ; 1.73 ; 2.95 ; 0.5$ & $15 \%$ & $5 \%$ & 4 \\
\hline & Mix 9 & $1 ; 1.73 ; 2.95 ; 0.5$ & $20 \%$ & $5 \%$ & 4 \\
\hline & $\operatorname{Mix} 10$ & $1 ; 1.73 ; 2.95 ; 0.5$ & $25 \%$ & $5 \%$ & 4 \\
\hline \multirow{5}{*}{$\begin{array}{l}\text { Group } \\
\text { (C) }\end{array}$} & Mix 11 & $1 ; 1.73 ; 2.95 ; 0.5$ & $0 \%$ & $10 \%$ & 4 \\
\hline & $\operatorname{Mix} 12$ & $1 ; 1.73 ; 2.95 ; 0.5$ & $10 \%$ & $10 \%$ & 4 \\
\hline & Mix 13 & $1 ; 1.73 ; 2.95 ; 0.5$ & $15 \%$ & $10 \%$ & 4 \\
\hline & $\operatorname{Mix} 14$ & $1 ; 1.73 ; 2.95 ; 0.5$ & $20 \%$ & $10 \%$ & 4 \\
\hline & Mix 15 & $1 ; 1.73 ; 2.95 ; 0.5$ & $25 \%$ & $10 \%$ & 4 \\
\hline \multicolumn{2}{|c|}{ Total number of cubes } & & & & 60 \\
\hline
\end{tabular}

\subsection{MATERIALS AND METHOD \\ 3.1Main Materials}

The main materials which were used in preparation of the concrete specimens for present investigation are as hereunder:

A. Cement :- Iraqi Ordinary Portland Cement with the specific gravity of 3.10

The cement properties are listed in table(2).

B. Sand :- Iraqi local sand from Al-Khazer area with the fineness modulus of (2.54).

The sand gradation is shown in table(3).

C. Gravel :- Iraqi local rounded gravel from AlKhazer area with a maximum size of $20 \mathrm{~mm}$. The specific gravity of the gravel is equal to (2.67).

D. Water: Potable drinking water is used for mixing and curing .

E. EPS particles are expanded polystyrene Spheres particles with a diameter range of 3-5 $\mathrm{mm}$, white in color. The density of these Polystyrene beads was $28 \mathrm{~kg} / \mathrm{m}^{3}$.

F. Silica Fume used is in conformance with the ASTM C 1240 specifications.

Table (2): Physical Properties of cement

\begin{tabular}{ccc}
\hline Test & Result & $\begin{array}{c}\text { Iraqi Specifications } \\
\text { NO.(5)1984 }\end{array}$ \\
\hline Specific gravity & 3.1 & $3-3.25$ \\
\hline Initial setting time & $167 \mathrm{~min}$. & $\min .1 \mathrm{hr}$ \\
\hline Final setting time & $3: 30 \mathrm{Hours}$ & $\mathrm{max} .10 \mathrm{hr}$ \\
\hline $\begin{array}{c}\text { Fineness(surface } \\
\text { area) }\end{array}$ & $299 \mathrm{~m}^{2} / \mathrm{kg}$ & $\mathrm{min.} 230 \mathrm{~m}^{2} / \mathrm{kg}$ \\
\hline
\end{tabular}


Table (3): Sieve Analysis of the sand

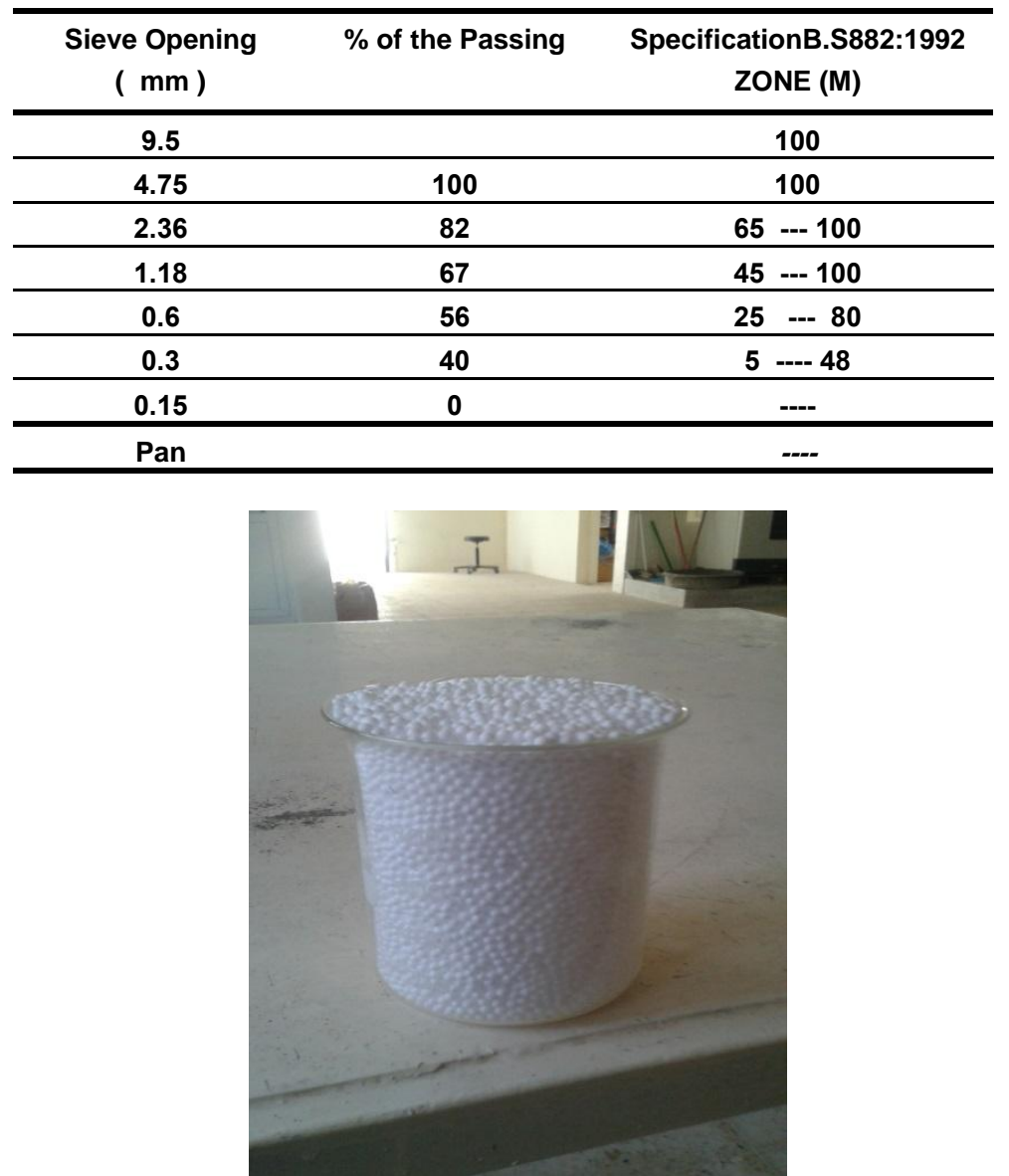

Fig.(1): Polystyrene beads used in the investigation

\subsection{Mix Design Principle}

According to the test results of the materials used in this research (cement, sand and gravel), concrete mix was designed by DoE method for a minimum strength of $30 \mathrm{MPa}$ at 28 days age. The concrete mix proportions were as follows:390:677:1153:195 (Cement, Sand, Gravel, Water) (For one cubic meter), in which mix proportions are equal to $1: 1.73: 2.95: 0.5$ (Cement, Sand, Gravel, Water).Water to cement ratio was fixed for all the mixes therefore, concrete workability differs from one mix to another depending on percent content of the silica fume and Polystyrene beads.

\subsection{Preparation of Specimens}

3.3.1 Mixing and CuringConcrete ingredients were mixed according to the designed mix proportions, the EPS beads were added, and finally water is added to form a concrete which was mixed manually. The plastic molds of $100 \mathrm{x}$ 
$100 \times 100 \mathrm{~mm}$ were oiled before filling the concrete. Before casting the concrete in the cubical molds, the internal surfaces of these molds were oiled .The molds were filled by concrete in two layers, and then placed on vibrating table to compact the concrete.
After the compaction has been completed, the excess concrete was removed from the molds with the help of trowel and the surface of concrete is leveled. After 24 hours, concrete cubes were remolded and taken to a water tank to be cured for 28

days.

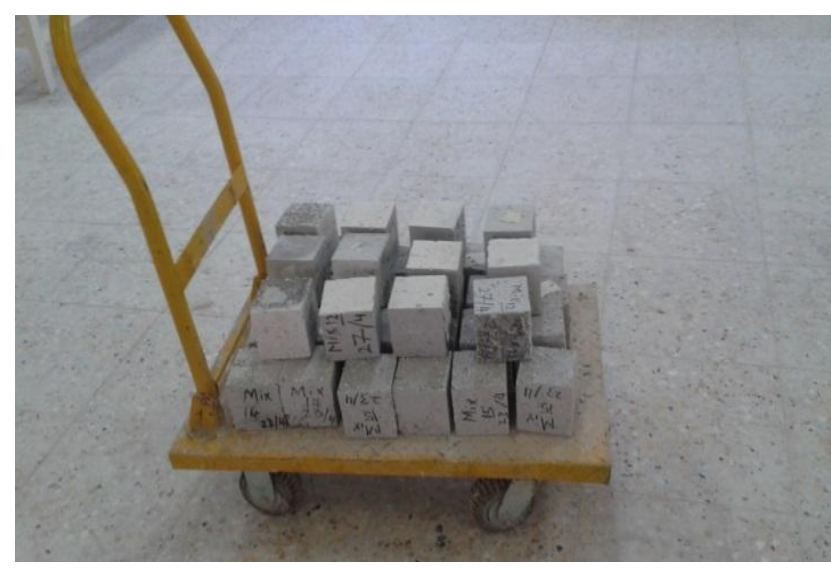

Fig.(2): Concrete cubes used in current research

\subsubsection{Concrete Testing}

\section{A. Compressive Strength Test}

After removal of concrete cubes from molds, the cubes were allowed to be dried in room temperature for about 5 hours before testing.
Compressive Strength Test was conducted based on BS EN 12390-3:2002. (14). Constant rate of loading, (2.0) MPs/s was applied to concrete cubes during compressive strength test.

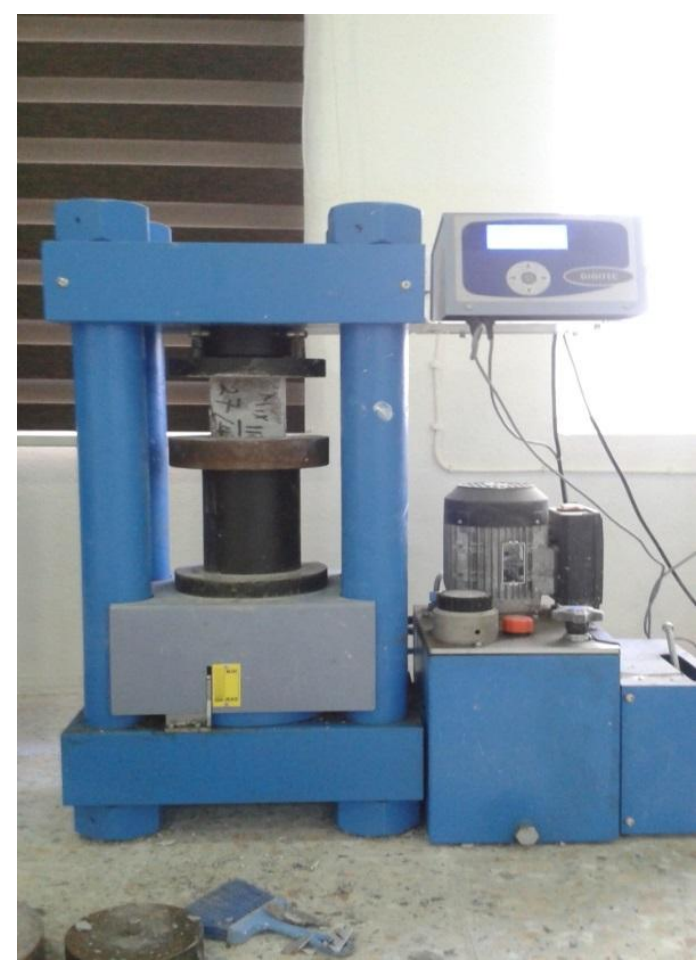


Fig.3.Compression Testing Machine

\section{B. Concrete Density}

Concrete cubes with different ratio of EPS beads by concrete volume were weighed at 28 days age. They were taken out of the water tank, dried for 5 hours and then weighed.

As it is mentioned before molds with dimension $100 \mathrm{~mm} \times 100 \mathrm{~mm} \times 100 \mathrm{~mm}$ were used for casting concrete; hence the volume of the samples is $0.001 \mathrm{~m}^{3}$.

Concrete density $\left(\mathrm{kg} / \mathrm{m}^{3}\right)$ is determined by dividing the net weight of concrete in kilogram by its volume in cubic meter.

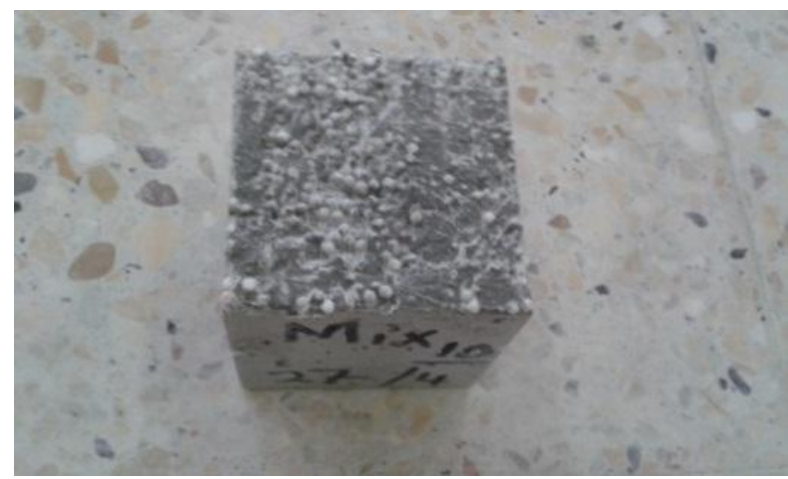

Fig.4.Concrete cube with EPS beads

\section{RESULTS AND DISCUSSION}

\section{A. Effect of EPS beads on concrete strength}

Test results of concrete compressive strength are shown in figures $(5,6,7$, and 8$)$. It is clear that the inclusion of EPS beads to the normal concrete (group A) reduces the concrete strength, this agree with the results of Aman Mulla and Amol Shlake (5). The reduction in strength is due the fact that cement concrete contact zone is stronger than the polystyrene granule material which has the lowest adhesion strength (15).
The inclusion of EPS beads by $10 \%$ to the volume of concrete reduces the concrete strength by $51 \%$, while the reduction in strength increases to $70 \%$ when the EPS beads increases to $25 \%$. After analyzing the results of (group A) it was shown that the polynomial equation $\left(\mathrm{Y}=0.0352 \mathrm{X}^{2}\right.$ $-1.7205 \mathrm{X}+31.59$ with $\mathrm{R}^{2}=0.9711$ ) was the best relation between the compressive strength and the EPS content.

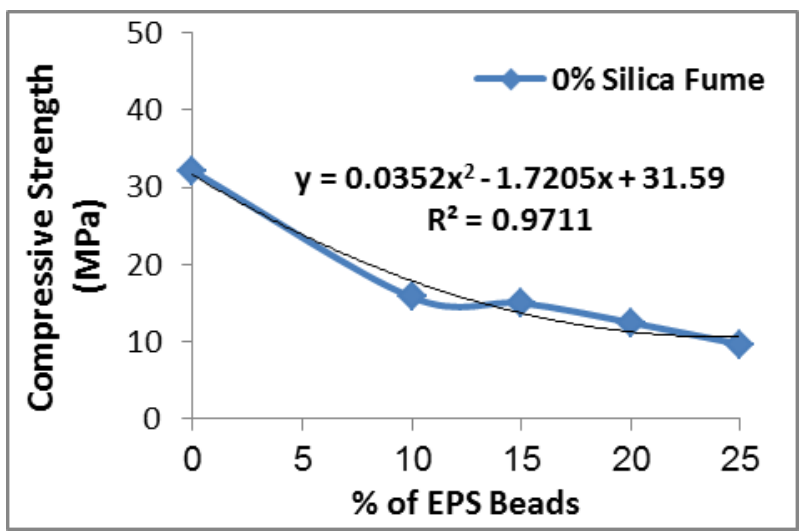

Fig. (5): Variation of concrete strength with EPS beads content (group A)

strength to by $39 \%$. For the same concrete, the reduction in concrete strength increases to $70 \%$, when the EPS beads increases to $25 \%$. After
For the silica fume concrete of $5 \%$ silica fume (group B), the inclusion of EPS beads by $10 \%$ to the volume of concrete reduces the concrete 
relation between the compressive strength and the EPS analyzing the results of (group B) it was shown that the polynomial equation $\left(\mathrm{Y}=0.0222 \mathrm{X}^{2}-\right.$ $1.485 \mathrm{X}+36.314$ with $\mathrm{R}^{2}=0.9892$ ) was the best

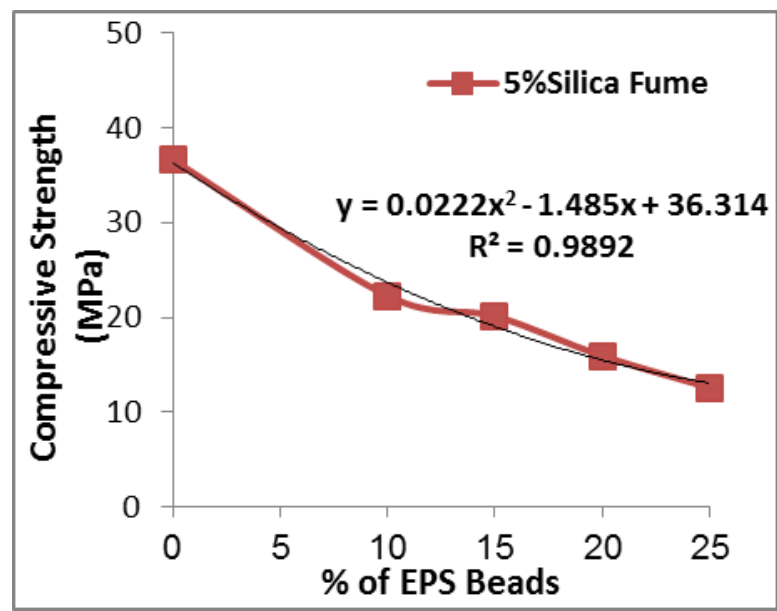

Fig. (6): Variation of concrete strength with EPS beads content (group B)

Test results of silica fume concrete with $10 \%$ silica fume shows that the inclusion of $10 \%$ EPS beads to the concrete causes a reduction in strength of about $61 \%$ with respect to the control one. This reduction in strength increases to $70 \%$ when the EPS beads increases to 25\%. After analyzing the results of (group C) it was shown that the polynomial equation $\left(\mathrm{Y}=0.042 \mathrm{X}^{2}-\right.$ $2.3635 \mathrm{X}+45.613$ with $\mathrm{R}^{2}=0.9924$ ) was the best relation between the compressive strength and the EPS content

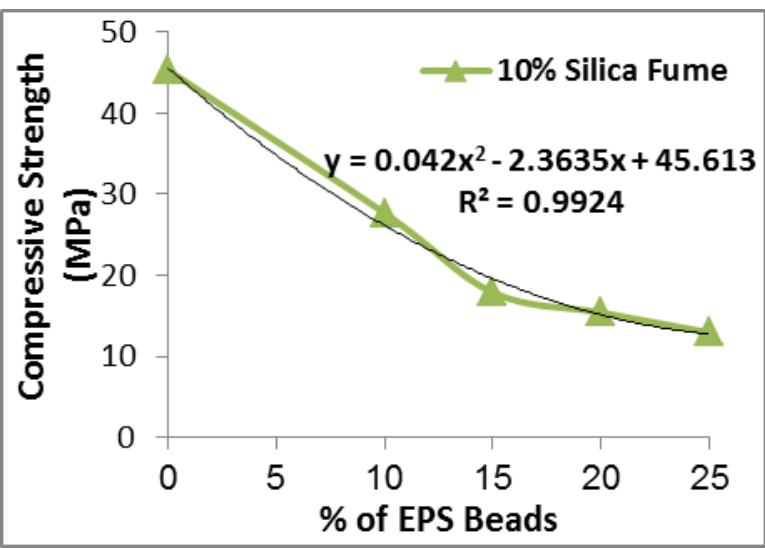

Fig.(7): Variation of concrete strength with EPS beads content (group C) 


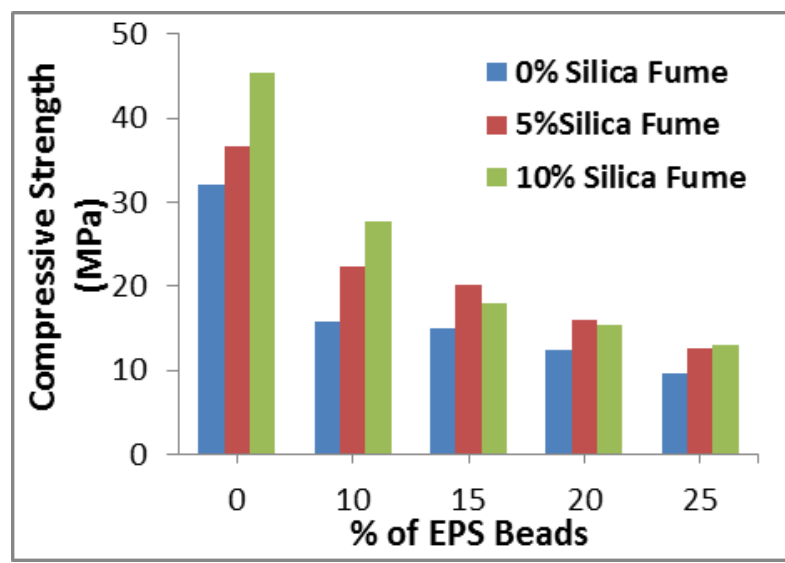

Fig. (8): Variation of concrete compressive strength with EPS beads content

It is concluded that the inclusion of EPS beads to concrete greatly reduces its strength. Also it is included that the reduction in strength follows the same trend for both normal and silica fume concretes.

\section{B. Effect of silica fume on concrete strength}

Figure (9) shows the effect of silica fume on concrete strength with respect to non silica fume concrete (Normal concrete).From the figure it is shown that the inclusion of silica fume by $5 \%$ replacement of cement, improves the concrete strength. This improvement in the strength of concrete is because of the high pozzolanic nature of the micro silica and its void filling ability in the concrete structure. (13).

The improvement in strength is about $14 \%$ for non EPS beads concrete, for this concrete of $10 \%$ EPS beads the improvement increases to $41 \%$, and for the concrete of $25 \%$ EPS beads the improvement was $30 \%$.

The inclusion of $10 \%$ silica fume to the normal concrete improves the concrete strength by $41 \%$. The strength improvement increase to $76 \%$ for the concrete of $10 \%$ EPS beads, while this improvement decreases to about $34 \%$ for concrete of $25 \%$ EPS beads.

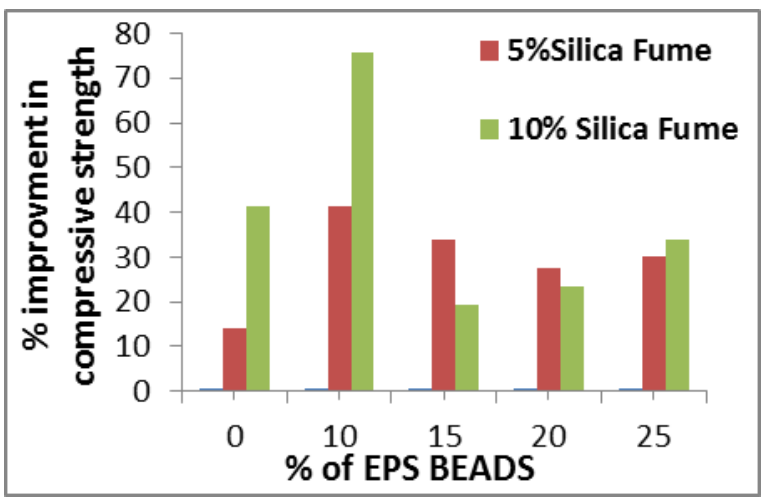

Fig. (9): Variation of \% improvement of compressive strength due to Silica-Fume content

It is concluded that the inclusion of silica fume to the concrete improves its strength for both normal concrete and EPS beads concrete.

From the test results it can be shown that the best benefit of adding silica fume to concrete can be taken when added to the concrete of $10 \%$ EPS beads by $5 \%$ replacement of cement as the improvement in strength is maximum (41\%).

For the concrete of $10 \%$ replacement of silica fume instead of cement the best benefit is taken from the silica fume addition when added to the concrete of also10\% EPS beads, for which the improvement in strength is about $76 \%$.

For concretes of 25\% EPS beads the improvement in strength is $30 \%$ and $34 \%$ due to the addition of silica fume by $5 \%$ and $10 \%$ respectively.

It is clear from the test results that structural concrete which is of strength $\geq 17 \mathrm{MPa}$ according to $\mathrm{ACl} 318$ Standard (Section 5.1.1)(16) can be 
manufactured with an addition of $15 \%$ EPS beads to concrete, if the cement is replaced by $5 \%$ or $10 \%$ silica fume.

For concrete of $(10 \%$ silica fume replacement of cement) the concrete gets strength of $27 \mathrm{MPa}$, even when it includes $10 \%$ EPS beads.

It is concluded that Structural concrete with EPS beads can be manufactured when silica fume is used in concrete.

This conclusion confirms with the findings of Aman Mulla and Amol Shlake (5) which states that (EPS) beads concrete has only scope of using in non-structural applications.

\section{Effect of EPS beads on concrete density}

The inclusion of EPS beads to the concrete reduces its density almost by the same percent as its added to concrete as it is shown in figure (10).The inclusion of EPS beads to concrete by $15 \%$ causes a reduction of $15.5 \%$ in its density. While this reduction in weight become $26.5 \%$ when the EPS beads content is $25 \%$.

The little deference between the percent reduction of the density and the percent addition of EPS beads is belonging to two reasons, the first one is the variation in the degree of concrete compaction of the cubes from batch to batch especially for high percent of EPS beads (20\% and $25 \%$ ) which belongs to the shrinkage of the beads volume, and the second is the weight of the EPS beads which is about 98\% air

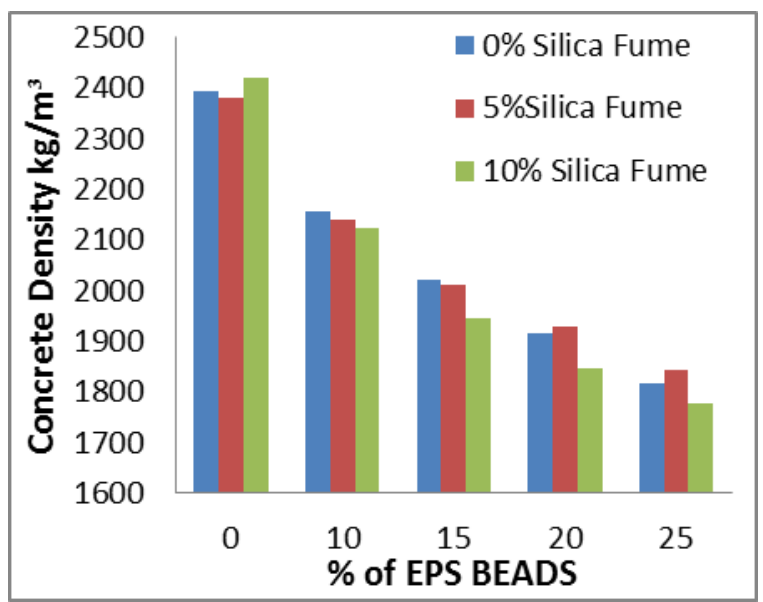

Fig. (10): Variation of concrete density with EPS beads content

\section{CONCLUSIONS}

Inclusion of silica fume to the concrete improves its strength for both normal concrete and concrete of EPS beads.

- Inclusion of EPS beads to the concrete greatly reduces the concrete strength.

- The best benefit from silica fume inclusion to the concrete of EPS beads is when the beads percent is $10 \%$ by volume of concrete.

- Structural concrete (Strength $\geq 17 \mathrm{MPa}$ ) with EPS beads can be manufactured when silica fume is used in concrete.

- The inclusion of EPS beads to the concrete reduces its density almost by the same percent as it's added to concrete volume.

\section{Acknowledgments:}

Authors are greatly thankful to the technician Heja Ahmed who is working at Duhok Technical Institute - Concrete Laboratory for his assistance.

\section{REFERENCES}

[1] Chen, B., Liu, J., \& Chen, L. Z. (2010). Experimental study of lightweight expanded polystyrene aggregate concrete containing silica fume and polypropylene fibers. Journal of Shanghai Jiaotong University

[2] Ewadh, H. M., \& Basri, N. A. (2012). Effectiveness of Polystyrene Beads as Aggregate Replacement Material to Recycle Solid Waste: A Study on Workability and Absorption Result of Concrete. International Journal of Scientific and Engineering Research, 3(8), 1-3 .

[3] Subhan, T. F. L. Compressive and Tensile Strength of Expanded Polystyrene Beads Concrete. SMARTek, 3(4).

[4] Kin, L. W., \& Ariffin, M. A. M. Strength Properties of Expanded Polystyrene Concrete and Cold Formed Steel Wall Frame Composite .

[5] Mulla, A., \& Shelake, A. (2016). Lightweight Expanded Polystyrene Beads Concrete. Int J Res Advent Technol, 17.

[7] Abd, S. M., Gh, D., Hattem, M., \& Khalil, D. (2016). EFFECTIVE REPLACEMENT OF 
FINE AGGREGATES BY EXPANDED POLYSTYRENE BEADS IN CONCRETE. Int. J. Eng. Res. Sci. Technol, 5, 45-53.

[6] Gawale, R., Mishra, S., Sambare, H., Kothari, J., \& Patil, A. P. M. LIGHT WEIGHT COCRETE BY USING EPS BEADS.

[8] Shi, W., Miao, L., Luo, J., Wang, J., \& Chen, Y. (2016). Durability of modified expanded polystyrene concrete after dynamic cyclic loading. Shock and Vibration, 2016.

[9] Cadere, C. A., Barbuta, M., Rosca, B., Serbanoiu, A. A., Burlacu, A., \& Oancea, I. (2018). Engineering properties of concrete with polystyrene granules. Procedia Manufacturing, $22,288-293$

[10] Ajileye, F. V. (2012). Investigations on micro silica (Silica Fume) as partial cement replacement in concrete. Global Journal of Research In Engineering, 12(1-E).

[11] Prof. Ghutke V. S\& Bhandari.p.s.(2014). Influence of silica fume on concrete. International Conference on Advances in Engineering \& Technology - 2014 (ICAET-2014) 44 | Page

[12] Neville A. M. and Brooks j. j., Concrete Technology, Person Education, England, 2004.

[13] BS EN 12390-3:2002: "Testing hardened concrete. Compressive strength of test specimens", British Standards Institution, London.

[14] ASTM C1240-04 ":" Standard Specification for Silica Fume Used in Cementitious Mixtures", American Society for Testing and Materials.

[15] Laukaitis, A., Žurauskas, R., \& Kerien, J. (2005). The effect of foam polystyrene granules on cement composite properties. Cement and Concrete Composites, 27(1), 41-47.

[16] ACI Committee. (2005). Building code requirements for structural concrete (ACI 31805 ) and commentary (ACI 318R-05). American Concrete Institute. 